\title{
EBSD Characterization of SCC in Alloy 182 Weld Metal
}

\author{
M. A. Othon and M. M. Morra \\ GE Global Research Center, One Research Circle, Niskayuna, NY 12309
}

In a prior paper we demonstrated the power of using EBSD to measure residual solidification induced plastic strains in the Ni-base weld filler metal alloy 182 [1]. In this work we use the same method to measure strains generated by a growing stress corrosion crack (SCC) in the same material.

After analyzing weld starting conditions using EBSD to map microstructure (dendrite size and orientation) and measure residual plastic strain, the same sample was then tested under conditions that induced growth of a SCC crack. One goal was to determine if a preferred crack path exists in alloy 182 weld metal due to either prior plastic strain fields or the crystallographic orientation of the dendrites. Another goal was to use EBSD data to determine whether a plastic zone forms ahead of a growing SCC front. EBSD generated misorientation maps of fatigue cracks clearly show regions indicative of a plastic zone [2]. Stress corrosion cracks similarly imaged are, however, marked more by the absence of distinct plastic zones ahead of the growing crack.

The alloy 182 weldment specimen and pre-test characterization techniques used for this study are described in an earlier publication [1]. For this work a compact tension (CT) specimen was machined from the same test block. After cracking, the specimen was electropolished at the crack propagation site, and a series of map measurements were performed in an effort to locate the identical grains previously studied (20mm from the top edge of the CT specimen). SCC crack characterization was limited to the exposed face of the specimen and so images are essentially one-dimensional views of a three-dimensional crack.

A comparison of post-test SCC path with a pre-test Euler map of a region that the crack was predicted to follow is shown in Figure 1. The pre-test Euler map across the weldment, located $20 \mathrm{~mm}$ above the weld root, is compared with the region into which the crack grew in Figures $1 \mathrm{~b}$ and 1c, respectively. The low crack growth rate obtained under these test conditions prevented the crack from reaching the predicted $20 \mathrm{~mm}$ zone but the relative position of the crack with respect to distance from the base metal weld interfaces was captured. The optical image and backscatter electron seen in Figure 1a and $1 \mathrm{~d}$ show the relative position of the stress corrosion crack with respect to the dendrites and the machined starter notch, respectively. More detailed images from near the crack front are shown in Figure 2. The crack path does not follow the dendrite boundaries, as seen in Figure $2 \mathrm{a}$, and in $10^{\circ}$ misorientation maps shown in Figures $2 \mathrm{~b}$ and $2 \mathrm{~d}$ no region of high misorientation is associated with the SCC crack. The next step for this sample will be to fatigue crack it in air, then measure by EBSD to map the strain distribution around the fatigue crack.

\section{References}

[1] Othon, M.A. and Morra, M.M., "EBSD Characterization of Residual Plastic Strain Across Alloy 182 Weld Joints", Proceedings: Microscopy and Microanalysis 2005 
[2] Brewer, L.N., Othon, M.A, Young, L.M., and T.M. Angeliu; "Misorientation Mapping for Visualization of Plastic Deformation via Electron Back-Scattered Diffraction", To Be Published in Microscopy and Microanalysis, 12, pp. 85-91, 2006
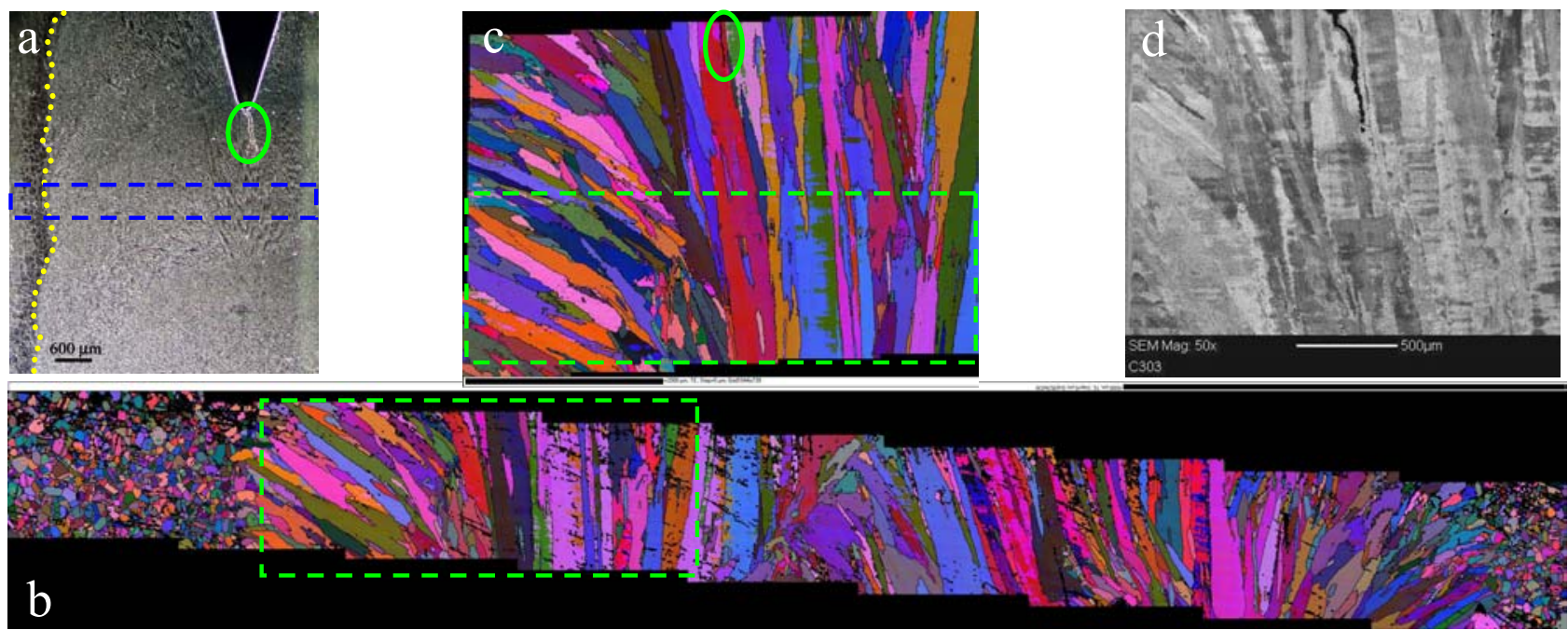

Figure 1. (a) Optical micrograph of SCC propagating from the machined CT notch, in green circle. Dotted yellow line indicates the weld/HAZ interface. The dashed blue box is the approximate region measured in Figure 1b. (b) Pre-test Euler map along a region across the alloy 182 weldment and $20 \mathrm{~mm}$ above the weld root prior to SCC testing. (c) Post-test Euler map that shows the region ahead of the SCC, in green circle. Dashed green boxes in figures $1 \mathrm{~b}$ and $1 \mathrm{c}$ illustrate the common region of the sample measured pre-test and post-test respectively. (d) BSE image of the weld region into which the crack is propagating.
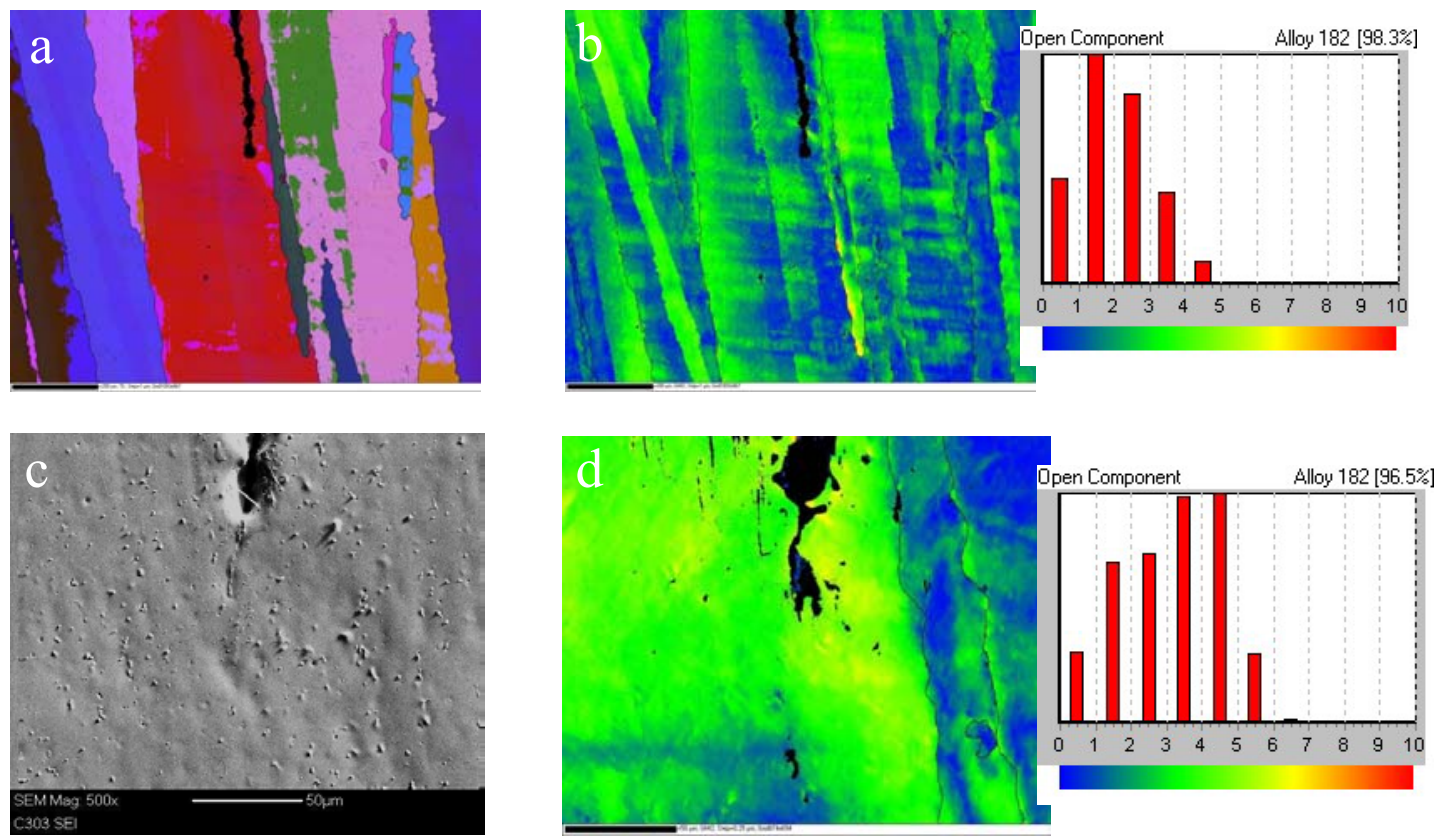

Figure 2. (a) Euler map of the region ahead of SCC crack. (b) $10^{\circ}$ misorientation map in the region around SCC crack. (c) Higher magnification secondary electron image of the crack tip. (d) $10^{\circ}$ misorientation map in the region at the crack tip. 